\title{
Anesthetic Treatment in Operations of Small Pelvic Organs Pathology
}

\author{
Taalaibek Atabaev¹, Zamirbek Arynov², Maksatbek Tashbaev³, Akperi Gaipova², \\ Gulshat Matkasymova², Iskenderbek Abdraiimov'², Absalam Zhunusov¹, Begmamat Nyshanov³, \\ Syrgak Bakirov ${ }^{3}$, Zhypargul Abdullaeva ${ }^{* *}$ (1)
}

\footnotetext{
${ }^{1}$ Department of Urology and Operative Surgery, Osh State University, Osh, Kyrgyzstan Kyrgyzstan

${ }^{3}$ Department of Surgical Diseases, Osh State University, Osh, Kyrgyzstan

${ }^{4}$ Science and Research Department, Osh State University, Osh, Kyrgyzstan

Email: *jypar.science@oshsu.kg
}

${ }^{2}$ Department of Surgical Disciplines with Traumatology Course, International Medical Faculty, Osh State University, Osh,

How to cite this paper: Atabaev, T., Arynov Z., Tashbaev, M., Gaipova, A., Matkasymova, G., Abdraiimov, I., Zhunusov, A., Nyshanov, B., Bakirov, S. and Abdullaeva, Z. (2021) Anesthetic Treatment in Operations of Small Pelvic Organs Pathology. Open Journal of Anesthesiology, 11, 355-360.

https://doi.org/10.4236/ojanes.2021.1112035

Received: November 21, 2021

Accepted: December 24, 2021

Published: December 27, 2021

Copyright (c) 2021 by author(s) and Scientific Research Publishing Inc. This work is licensed under the Creative Commons Attribution International License (CC BY 4.0).

http://creativecommons.org/licenses/by/4.0/

\begin{abstract}
The article presents data on the surgical treatment of 405 patients with pelvic organ surgical and gynecological diseases. When using regional anesthesia during operations in the lower abdominal cavity of patients with pelvic pathology, a smoother operation course and early postoperative period were observed compared with general anesthesia use. In this work, 405 patients with surgical and gynecological diseases of pelvic organs, operated in the surgical and gynecological departments were analyzed. When using regional anesthesia, it was observed that intraoperative blood loss in patients and consumption of narcotic analgesics in the postoperative period decreases.
\end{abstract}

\section{Keywords}

Surgery, Pelvic Organ Diseases, Anesthesia, Treatment, Pathology

\section{Introduction}

When choosing anesthesia for operations in the lower part of the abdominal cavity and on the pelvic organs in recent years, regional anesthesia methods are most often preferred: epidural and spinal anesthesia. Epidural approach including epidural anesthesia/analgesia, with or without an epidural catheter remains as the gold standard for analgesia in abdominal surgery interventions [1] [2]. Regional anesthesia is most effective in contrast to other methods in pain relief during labor and should be always available in obstetric institutions [3]. Anesthetic considerations during abdominal wall reconstruction are depending on patients' 
medical conditions, patients who have increased Body Mass Index (BMI) [4] undergoing anesthesia for abdominal wall surgery force with several anesthetic challenges [5]. The use of regional anesthesia provides stable hemodynamics, especially in elderly patients, and provides good neurovegetative protection [6]. Peripheral nerve block techniques have also been associated with adverse effects such as muscle weakness and the risk of falls in the postoperative period [7]. Sufficiently reliable, long-term anesthesia even with a single injection of anesthetic, allows minimal impact on patients vital organs and systems condition, as well as metabolism in a high degree of operational risk and a number of concomitant diseases [8] [9].

However, some aspects of the use of regional anesthesia require further research [10]. It is especially interesting and relevant to compare these types of anesthesia with one of the types of widespread general anesthesia [11] [12] [13].

Nevertheless, modern methods in general anesthesia with mechanical ventilation showed a few serious disadvantages. The evaluation criterion was ventilation failure within 72 hours after mechanical ventilation, which was initiated with the anesthesia ventilator [14]. Inadequate Mechanical Ventilation (MV) settings can lead to both atelectasis and lung overdistention [15], which can be restored by effective respiratory mechanics during general anesthesia [16]. Additional disadvantages include the use of large doses of sedatives [17], narcotic analgesics and anesthetics, the adverse effects of inhalation and intravenous anesthetics, muscle relaxants, among which it is difficult to avoid polyprogmasia, post-anesthetic depression, vomiting and rapid cessation of analgesia in the early postoperative period.

All these contribute to the development of a large number of complications from the lungs, cardiovascular and other systems in the perioperative period, especially in patients with severe somatic pathology with various types of combined general anesthesia [18].

In addition to the complications diagnosed in the perioperative period, various complications arise in the more distant period. In patients operated on with the use of intubation anesthesia with mechanical ventilation [19], the use of narcotic analgesics for postoperative analgesia in usual dosages causes depression of consciousness, and the function of external respiration can decrease by $40 \%-70 \%$ compared with the initial values. Under conditions of general endotracheal anesthesia [20] [21], artificial ventilation of the lungs disrupts the natural mechanisms of respiration and blood circulation, the relationship between surgical stimuli, general anesthetics and awareness is represented in Figure 1.

The research purpose in our study was to comparatively analyze results of epidural, spinal, intravenous and general anesthesia during operations of the pelvic organs.

\section{Research Methods and Materials}

In this work, 405 patients with surgical and gynecological diseases of pelvic organs operated in surgical and gynecological departments analyzed. In this work, 


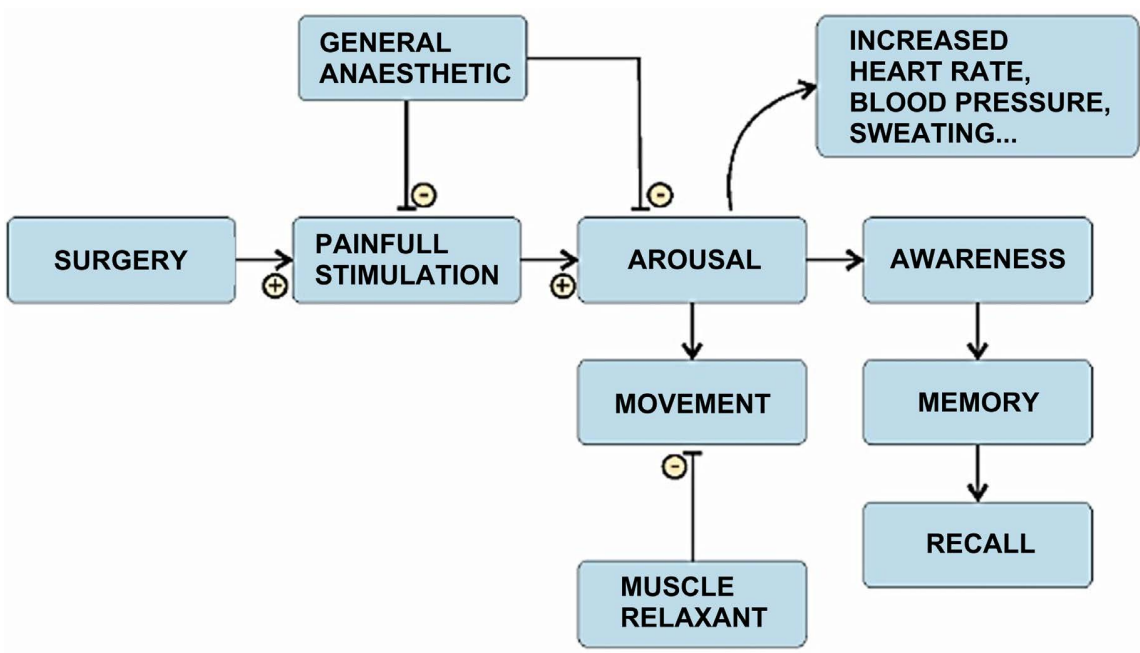

Figure 1. Relationship between surgical stimuli, general anesthetics and awareness (represented from reference [20]).

inclusion criteria were medicines economical use, anesthesia safety and their less complication; exclusion criteria were patients' ethnicity, nation, severe mild cases quantity and residence. For comparison of surgical intervention results, we consider women with different age in our work. Patients were divided into 4 groups, depending on the type of anesthesia they prescribed; epidural anesthesia was performed in 100 patients by puncture of the epidural space at the level from L1 to L4. As the local anesthetics lidocaine $(600 \mathrm{mg})$ was used.

\section{Results and Discussions}

There were 2 patients under the age of $20(0.5 \%)$; a larger group consisted of women aged from 30 to 60 years were 374 patients (92.3\%); people over 60 years old were $29(7.2 \%)$ marked as severe patients group. The preparations were injected into $15-20 \mathrm{ml}$ of Ringer's solution. Spinal anesthesia was performed in 100 patients by spinal puncture at the level from L1 to L4. A $2 \%$ solution of lidocaine in a volume of $3 \mathrm{ml}$ was used. Patients' distribution by age is shown in Table 1.

Intravenous anesthesia was administered to 85 patients. It was performed according to the generally accepted method using fentanyl, droperidol with barbiturates with mechanical ventilation against the background of total muscle relaxation and mechanical ventilation.

General endotracheal anesthesia was performed in 120 patients, performed with sodium thiapental at a calculated dose of $4-5 \mathrm{mg} / \mathrm{kg}$, focusing on clinical signs such as loss of verbal contact, absence of ciliary and corneal reflexes, pupillary constriction with weak photoreaction, apnea, decreased muscle tone.

Provision of myoplegia for intubation and maintenance of muscle relaxation during the operation was carried out with a muscle relaxant of medium duration of action arduan. Ditylin induction dose for intubation was $0.4 \mathrm{mg} / \mathrm{kg}$. The maintenance dose of Arduan was $0.2-0.3 \mathrm{mg} / \mathrm{kg}$. After tracheal intubation, artificial 
Table 1. Patients' distribution by age.

\begin{tabular}{ccccccccc}
\hline & \multicolumn{7}{c}{ Patients' age distribution in years } \\
\hline & Before 20 & $21-30$ & $31-40$ & $\mathbf{4 1 - 5 0}$ & $\mathbf{5 1 - 6 0}$ & $\begin{array}{c}\text { Older } \\
\text { than 61 }\end{array}$ & Total \\
\hline $\begin{array}{c}\text { Absolute number } \\
\text { Percentage }\end{array}$ & 2 & 48 & 99 & 143 & 84 & 29 & 405 \\
\hline
\end{tabular}

ventilation of the lungs was started with a RO-6 apparatus (Russia). After tracheal intubation, a nasogastric tube was installed in all patients to reduce the risk of perforation of the abdominal organs and to prevent postoperative nausea and vomiting. The probe was removed before extubation, and the gastric contents were actively aspirated. Intraoperative iifusion therapy was $10-15 \mathrm{ml} / \mathrm{kg} / \mathrm{min}$ of crystalloid and colloid solutions according to indications.

In patients with initial hypertension, operated with the use of spinal anesthesia and epidural anesthesia, blood pressure always decreased compared to the preoperative period which was $120 / 80 \mathrm{~mm} \mathrm{Hg}$ and contributed to decrease in operating blood loss by $20 \%-25 \%$. Adequate pain relief was achieved in all patients during the operation. Hemodynamics were stable. No complications associated with anesthesia in patients were observed.

When using epidural anesthesia with a mixture of local anesthetic and narcotic analgesic, the duration of anesthesia was averaged to $6.56+0.55$ hours. With spinal anesthesia, patients began to feel pain $1.2+0.35 \mathrm{~h}$ after operation. With general and intravenous anesthesia, pain appeared on average $1.6+0.28 \mathrm{~h}$ after the end of anesthesia. Patients operated on under general and intravenous anesthesia on the first day after the operation were injected intramuscularly every 4 hours with a $2 \%$ solution of promedol. After epidural and spinal anesthesia, promedol was administered once a day. The course of the early postoperative period was smoother in patients operated under regional anesthesia. This is especially noticeable in patients operated under epidural anesthesia.

Thus, the optimal method of anesthesia during surgical interventions in patients with pelvic pathology is regional anesthesia, which does not aggravate hemodynamic disturbances, but, on the contrary, contributes to their normalization.

\section{Conclusions}

In summary, we came to the following conclusions:

1) When using regional anesthesia during operations in the lower floor of the abdominal cavity of patients with pelvic pathology, there is a smoother course of the operation and the early postoperative period than with general anesthesia;

2) When using regional anesthesia, intraoperative blood loss decreases, and the consumption of narcotic analgesics in the postoperative period decreases;

3) Regional anesthesia during operations in the abdominal cavity lower part, 
especially in elderly patients, is the gentlest method of anesthesia, including in the presence of concomitant diseases.

\section{Conflicts of Interest}

The authors declare no conflicts of interest regarding the publication of this paper.

\section{References}

[1] Makhovsky, V.Z., Ovanesov, B.T. and Madagov, L.A. (2002) Simultaneous Combined Operations in Emergency and Elective Surgery. Surgery, 7, 41-46.

[2] Fernandes, H., Azevedo, A.S., Ferreira, T.C., Santos, S.A., Rocha-Filho, J.A. and Vieira, J.E. (2021) Ultrasound-Guided Peripheral Abdominal Wall Blocks. Clinics, 76, Article No. e2170. https://doi.org/10.6061/clinics/2021/e2170

[3] Kulikov, A.V. and Shifman, E.M. (2013) Pain Relief during Labor. Clinical Guidelines. Regional Anesthesia and Acute Pain Management, 7, 60-70.

[4] Sakibaev, K., Kyzy, K.Z., Tashmatova, N., Klochkova, S., Atabaev, I., Nikityuk, D., Abdullaeva, Z., Dzhumaeva, L., Alexeeva, N. and Satylganov, I. (2021) Somatotypological Features of the Skin Fat Fold Thickness in Ethnic Kyrgyz Women. Forensic Medicine and Anatomy Research, 9, 1-9. https://doi.org/10.4236/fmar.2021.91001

[5] Slabach, R. and Suyderhoud, J.P. (2012) Anesthetic Considerations for Abdominal Wall Reconstructive Surgery. Seminars in Plastic Surgery, 26, 12-17. https://doi.org/10.1055/s-0032-1302460

[6] Koryachkin, V.A. and Strashnoi, V.I. (2000) Spinal and Epidural Anesthesia. Manual for Doctors, Saint Petersburg, 11-14.

[7] Eduardo, P., Surinam, G.A., Andrea, U.G., Rodrigo, F.J., Edoardo, M.R., Efraín, D. and César, B.C. (2021) Lumbar-Sacral Plexus Block Anesthesia versus General Anesthesia for Total Hip Arthroplasty: Case Control Study. Open Journal of Anesthesiology, 11, 259-268. https://doi.org/10.4236/ojanes.2021.119025

[8] Yeoh, C., Teng, H., Jackson, J., Hingula, L., Irie, T., Legler, A., Levine, C., Chu, I., Chai, C. and Tollinche, L. (2019) Metabolic Disorders and Anesthesia. Current Anesthesiology Reports, 9, 340-359. https://doi.org/10.1007/s40140-019-00345-w

[9] Johnston, D.F. and Turbitt, L.R. (2021) Defining Success in Regional Anaesthesia. Anaesthesia, 76, 40-52. https://doi.org/10.1111/anae.15275

[10] Mehmood, R., McGuire, A.J., Mansoor, Z., Fink, A.B. and Atanasov, G. (2021) Regional Anaesthetic Techniques and Their Implications during the COVID Pandemic. SN Comprehensive Clinical Medicine, 3, 2222-2228. https://doi.org/10.1007/s42399-021-01035-7

[11] Heydinger, G., Tobias, J. and Veneziano, G. (2021) Fundamentals and Innovations in Regional Anaesthesia for Infants and Children. Anaesthesia, 76, 74-88. https://doi.org/10.1111/anae.15283

[12] Lie, S.A., Wong, S.W., Wong, L.T., Wong, T. and Chong, S.Y. (2020) Practical Considerations for Performing Regional Anesthesia: Lessons Learned from the COVID-19 Pandemic. Canadian Journal of Anaesthesia, 67, 885-892. https://doi.org/10.1007/s12630-020-01637-0

[13] Chen, D.X., Yang, L., Ding, L., Li, S.Y., Qi, Y.N. and Li, Q. (2019) Perioperative Outcomes in geriatric Patients Undergoing Hip Fracture Surgery with Different Anesthesia 
Techniques: A Systematic Review and Meta-Analysis. Medicine, 98, Article ID: e18220. https://doi.org/10.1097/MD.0000000000018220

[14] Gouel-Cheron, A., Couffignal, C., Elmaleh, Y., Kantor, E. and Montravers, P. (2020) Preliminary Observations of Anaesthesia Ventilators Use for Prolonged Mechanical Ventilation in Intensive Care Unit Patients during the COVID-19 Pandemic. Anaesthesia, Critical Care \& Pain Medicine, 39, 371-372.

https://doi.org/10.1016/j.accpm.2020.04.009

[15] Fogagnolo, A., Montanaro, F., Al-Husinat, L., Turrini, C., Rauseo, M., Mirabella, L., Ragazzi, R., Ottaviani, I., Cinnella, G., Volta, C.A. and Spadaro, S. (2021) Management of Intraoperative Mechanical Ventilation to Prevent Postoperative Complications after General Anesthesia: A Narrative Review. Journal of Clinical Medicine, 10, Article ID: 2656. https://doi.org/10.3390/jcm10122656

[16] Ball, L., Costantino, F., Fiorito, M., Amodio, S. and Pelosi, P. (2018) Respiratory Mechanics during General Anaesthesia. Annals of Translational Medicine, 6, Article No. 379. https://doi.org/10.21037/atm.2018.09.50

[17] Moreira, F.T. and Neto, A.S. (2016) Sedation in Mechanically Ventilated Patients-Time to Stay Awake? Annals of Translational Medicine, 4, Article No. 382. https://doi.org/10.21037/atm.2016.09.37

[18] Moretto, A., Bosatra, M.G., Marchesini, L. and Tesoro, S. (2018) Anesthesiological Risks in Mucopolysaccharidoses. Italian Journal of Pediatrics, 44, Article No. 116. https://doi.org/10.1186/s13052-018-0554-1

[19] Han, Q., Wu, S., Chen, H., Wang, L. and Zhang, C. (2021) The Choice of Anesthesia for Acute Abdomen Surgery Patients and Its Influence on Gastrointestinal Function Recovery. American Journal of Translational Research, 13, 9621-9626.

[20] Potyk, D.K. and Raudaskoski, P. (1998) Overview of Anesthesia for Primary Care Physicians. The Western Journal of Medicine, 168, 517-521.

[21] Musizza, B. and Ribaric, S. (2010) Monitoring the Depth of Anaesthesia. Sensors, 10, 10896-10935. https://doi.org/10.3390/s101210896 